\title{
Temperature measurements of pacemaker leads in a 1.0T high field open MRI using various MR sequences: initial results
}

\author{
Sebastian A Seitz ${ }^{1}$, Julian J Ebner², Gerriet Petry ${ }^{3}$, Evangelos Giannitsis ${ }^{2}$, Olaf Dössel ${ }^{2}$, Hugo A Katus ${ }^{2}$, \\ Henning Steen ${ }^{2^{*}}$
}

From 2011 SCMR/Euro CMR Joint Scientific Sessions

Nice, France. 3-6 February 2011

\section{Introduction}

Magnetic resonance imaging (MRI) is a valuable diagnostic method for many cardiovascular diseases. To date, patients with pacemakers are contra-indicated for cardiac MRI exams due to several effects that can occur during the MRI procedure: a) heating of the lead-tip, and b) less hazardous sensing errors and device malfunctions. Almost all measurements on MRI pacemaker compatibility have been conducted on classic 1.5 or $3 \mathrm{~T}$ cylindrical wholebody MRI systems. In contrast, this study focused on the use of a high field open MRI (HFO) system due to its advantageous properties of RF fields which are commonly made responsible for the induction of lead heating.

\section{Purpose}

Determine the feasibility of MRI examinations of patients with cardiac pacemakers using an open $1.0 \mathrm{~T}$ MRT system and realistic cardiac imaging sequences.

\section{Methods}

Two high energy (1.+2.) and two realistic clinical cardiac (3.+4.) MR-sequences with artificial ECG-triggering at 60/min were used on the 1.0T HFO system: 1 . T2-TSE $(\mathrm{TR} / \mathrm{TE}=177 / 38 \mathrm{~ms}$; TSE-factor $=16$; time $=58 \mathrm{~s}$; flip-angle $=$ $\left.90^{\circ}\right)$; 2. 3-D bTFE $(\mathrm{TR} / \mathrm{TE}=4.7 / 2.4 \mathrm{~ms}$; TFE-factor $=6$; time $=382$; ;lip -angle $=70^{\circ}$;TFE- shot -duration $=34 \mathrm{~ms}$;TFEshots $=532), 3$. SSFP-cine $(\mathrm{TR} / \mathrm{TE}=4.7 / 2.2 \mathrm{~ms}$; TFE-factor $=$ 16 ; time $=90 \mathrm{~s} ;$ flip - angle $=70^{\circ} ;$ TFE- shot -duration $=76 \mathrm{~ms}$; TFE-shots=76), 4. 3D-FFE multi-shot (inversion-recovery; $\mathrm{TR} / \mathrm{TE}=3.9 / 1.3 \mathrm{~ms}$; TFE-factor $=21$; time $=23 \mathrm{~s}$; flip-angle $=15^{\circ}$; TFE-shot-duration $=157 \mathrm{~ms}$;TFE shots=46). Two types of bipolar cardiac pacing leads were evaluated: a) conventional lead (Medtronic Capsurefix Novus), 2. MR compatible lead (Medtronic Capsurefix MRI SureScan) both connected to a St. Jude Frontier II pacemaker. The pacemaker/lead system was placed in a saline-filled Plexiglas phantom imitating three clinically common lead positions
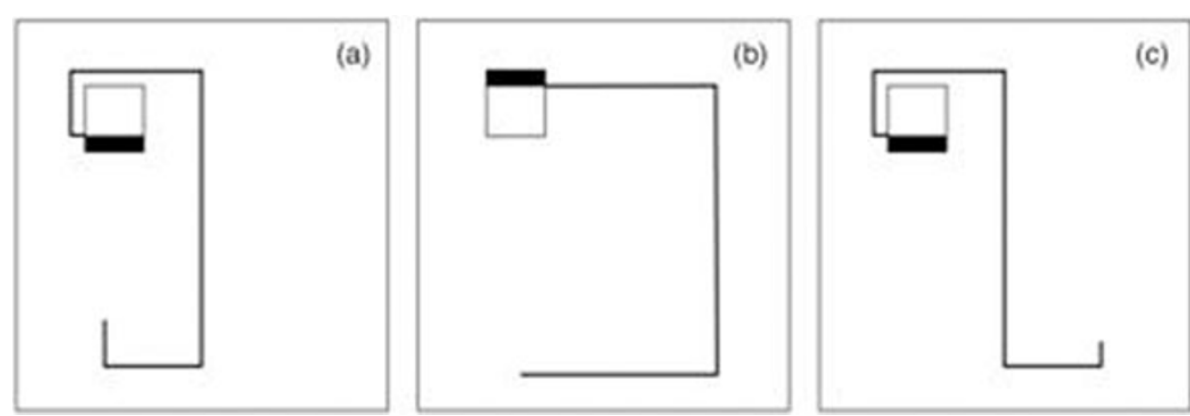

Figure 1 Pacemaker/lead configurations imitating common implantation patterns.

${ }^{2}$ University Heidelberg, Heidelberg, Germany

Full list of author information is available at the end of the article

(c) 2011 Seitz et al; licensee BioMed Central Ltd. This is an open access article distributed under the terms of the Creative Commons 


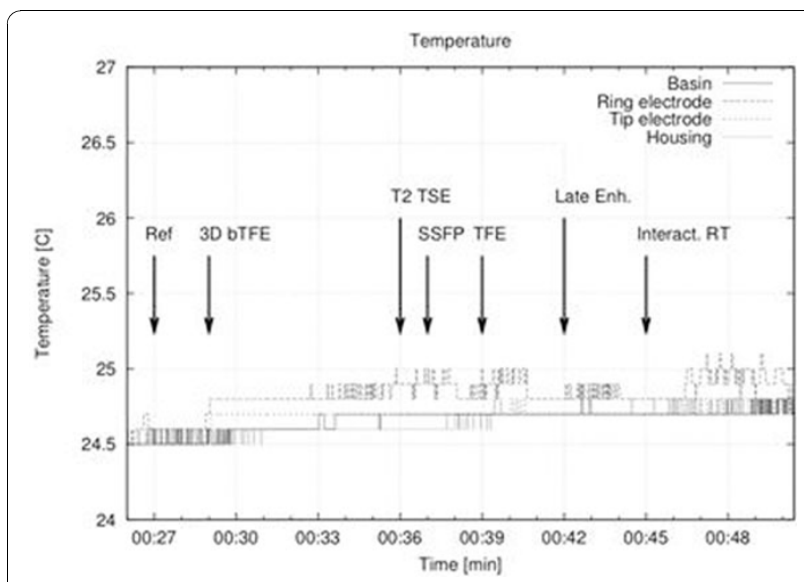

Figure 2 Development of temperature at four different positions (Tip electrode, ring electrode, pacemaker housing, basin/phantom) while exposed to a series for MRI sequences, pacemaker/lead configuration as shown in Fig. 1(a)

(figure 1). Temperature measurements were captured with a fiber-optic measurement system.

\section{Results}

The highest temperature increase $\left(0.6{ }^{\circ} \mathrm{C}\right)$ was observed in the (a) configuration when exposed to the realtime interactive sequence (see fig. 2). In none of the utilized scan protocols severe heating could be measured.

\section{Conclusions}

In-vitro measurement of an MR compatible and a regular pacemaker lead in geometrically realistic positions in an HFO open MRI system showed no relevant tip heating for both ECG-gated high energy as well as clinically used cardiac MR sequences. Further in-vivo research has to be conducted to clarify the relevance of these findings.

\section{Author details}

${ }^{1}$ Karlsruhe Institute of Technology (KIT), Karlsruhe, Germany. ${ }^{2}$ University Heidelberg, Heidelberg, Germany. ${ }^{3}$ Heidelberg Health System, Heidelberg, Germany.
doi:10.1186/1532-429X-13-S1-P65

Cite this article as: Seitz et al:: Temperature measurements of pacemaker leads in a 1.0T high field open MRI using various MR sequences: initial results. Journal of Cardiovascular Magnetic Resonance 2011 13(Suppl 1):P65.
Submit your next manuscript to BioMed Central and take full advantage of:

- Convenient online submission

- Thorough peer review

- No space constraints or color figure charges

- Immediate publication on acceptance

- Inclusion in PubMed, CAS, Scopus and Google Scholar

- Research which is freely available for redistribution

Submit your manuscript at www.biomedcentral.com/submit 